\title{
Detailing of the Igneous Rock Lithology in Wells - Logging Data from the Carboniferous, West Junggar Basin, China
}

\author{
Kun Wang \\ Department Petroleum Geology \\ Research Institute of Petroleum Exploration and \\ Development, PetroChina \\ Beijing, China \\ e-mail: wangkuntoby@163.com
}

Suyun $\mathrm{Hu}$

Department Petroleum Geology

Research Institute of Petroleum Exploration and

Development, PetroChina

Beijing, China

e-mail: 124426184@qq.com

\author{
Kui Ma \\ Department Petroleum Geology \\ Research Institute of Petroleum Exploration and \\ Development, PetroChina \\ Beijing, China \\ e-mail: 286476422@qq.com
}

\author{
Cheng Qin \\ Chongqing Research Institute \\ China Coal Technology Engineering Group \\ Chongqing, China \\ e-mail: 404632700@qq.com
}

\begin{abstract}
The carboniferous igneous rock in the west Junggar Basin mainly composed of tuff, andesite, basalt and volcanic breccia is very hard to exactly distinguish via geological logging. Based on logging data coupled with cores, logging cross plot, imaging logging and fisher discriminant was used to identify the lithology. The effect of cross plot is too confused to distinguish all the lithology. Imaging logging can effectively visualized divide four types of igneous rock, but time and human resources are essential. Fisher discriminant analysis can integrate several logging information and achieve auto identification, decreasing human resource cost and time consumption. With the combination of three methods, modified lithology section is more abundant in lithology and more accurate in lithology, depth and thickness. The new section can be well useful in reservoir research.
\end{abstract}

Keywords- lithology detailing; logging data; igneous rock; the Carboniferous; Junggar Basin

\section{INTRODUCTION}

Igneous rock has been a new domain of the world wide hydrocarbon prospect. Igneous rock reservoirs were found in many countries such as American, Cuba and Mexico [15]. This kind of reservoir was also been found in the Carboniferous, west Junggar Basin with considerable reserves [6-8]. Hydrocarbon in the Carboniferous igneous rock in the Chepaizi uplift located in the west Junggar Basin were first discovered in 2011 due to the drilling of well P61. The convert production of the following drilling well P66 was 11 ton per day, showing good prospect potential of the igneous reservoir. At present, the prospect stage of Carboniferous igneous rock reservoir is still primary and the drillings aimed at carboniferous igneous rock are still limited, restricting the hydrocarbon prospect. Drilling and outcrops show that four rock types occurs in the carboniferous which are hardly distinguished by geological logging, causing difficulty of identifying the lithology with best reservoir quality. This paper used well logging and cores data to detail the lithology section of igneous rock, facilitating reservoir analysis.

\section{GEOLOGICAL SETTING}

The Chepaizi uplift is located in the west Junggar Basin, surrounded by the Zaire Mountain in the north and west, Sikeshu depression in the south and Hongche fault zone in the east (Fig. 1). It is a secondary tectonic unit of the west upwarping region [9-10]. Formed in later Hercynian, the Chepaizi uplift experienced intense uplift in the Indosinian and Yanshanian and slow sedimentation in Himalayanian, resulting to a successive paleouplift [11-12]. With large upwarping area, the uplift has NW trend triangular shape, sloping toward SE. The uplift is also located near two hydrocarbon generating depressions and in the trending region of hydrocarbon migration. The location of the uplift is very good for the hydrocarbon migration [13]. The carboniferous composed of igneous rock is the base of the uplift. The lithology of igneous rock contains tuff, andesite, basalt and volcanic breccia, which are difficult to identify in geological logging.

\section{IGNEOUS ROCK LITHOLOGY DETAILING}

Accurate identification for the lithology of igneous rocks is basic research of igneous reservoir, core slice identification is an effective and direct way to identify igneous. The logging work of drilling sites is restricted by time, experience and environmental, the acquired original logging profiles often poor accuracy and low reliability, for complex lithology of igneous rock formations is even more so. The obtaining for lithology logging profiles often 
required comprehensive comparison for drilling coring data and lithic materials. The more intensive coring, the higher acucuracy the logging is. However, the cost of drilling coring is high and takes long time on preparing the preparation of thin slices, which restrict the promotion of the oil and gas exploration work in time. Logging materials can continuously, truly reflect the physical characteristics of the formation. Different rocks have different physical properties, which makes it is possible for utilizing a variety logging information to identify lithology [14-15]. In this paper, we first used conventional logging data and image logging to identify the complex lithology of igneous rock.

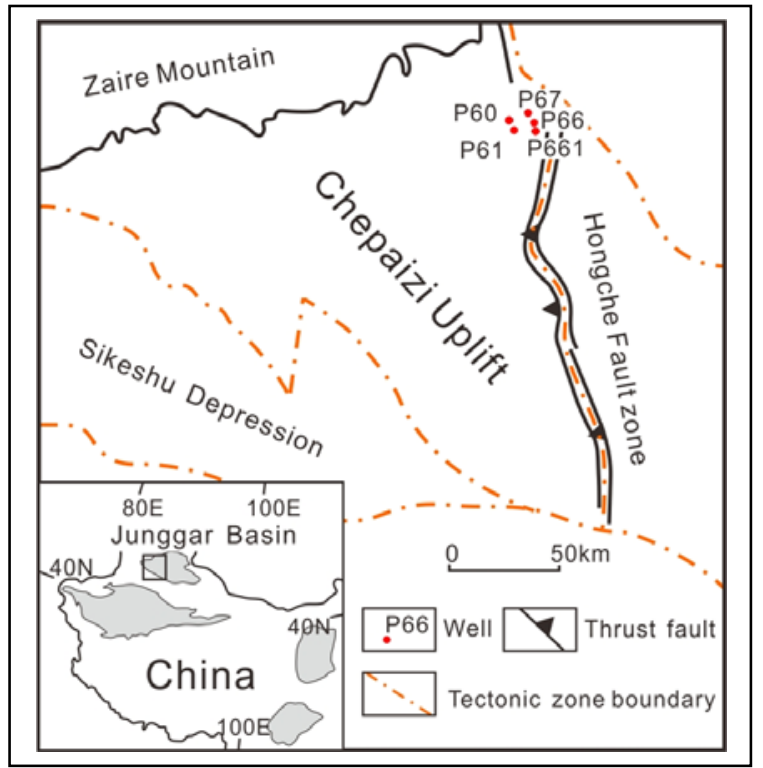

Figure 1. Location of the Chepaizi uplift and the tectonic zone division of the west Junggar Basin.

\section{A. Logging data cross plot}

Well logging cross plot is a general method for igneous rock distinguishing [16-17]. Logging data of known lithology were used to establish the proper distinction plot. In the Chepaizi uplift, the basalt and andesite generally have lower GR value and higher RD value, and can be well distinguished from tuff and breccia, but others are hardly distinguished. Using this cross plot, it is difficult to differentiate volcano breccia and tuff with low GR values (Fig. 2 a). In cross plot of DEN versus GR, the density of volcanic breccia is generally low, thus, it is well distinguished from tuff, but others are still mix (Fig. 2 b). Generally, based on conventional logging data, igneous rock lithology can be roughly distinguished; but, multiplicity of cross plot analysis needs constrain of other methods to obtain more accurate results.

\section{B. Imaging logging}

The ability of conventional log materials to identify the composition and structure of volcanic is relative limited, imaging logging can better reflect the macro-structure of volcanic rock [18]. The relationship between carboniferous cores and imaging logging is established. On the basis of accurately describing the imaging logging characteristics of different lithology, we can establish the identification plot of Carboniferous igneous lithology.

Tuff: The tuff in the Chepaizi uplift presents black or gray with tuffaceous texture, Massive structure and inhomogeneous structure. The fractures are generally filled by calcite and quartz. In the logging image, the Massive structure and inhomogeneous structure can be well identified and the colour is general dull with few bright block and vugs (Fig. 3).

Andesite: The Andesite generally presents gray or gray black. Inhomogeneous structure, Massive structure and vesicular structure can be seen in cores. Some pores were filled by calcite and quartz and formed amygdaloidal structure. Scattered dull spots which are the vesicular structure of low resistance occur in the imaging logging picture of andesite. Bright spots and inhomogeneous structure are also founded (Fig. 3).

Basalt: The basalt in the Chepaizi uplift presents gray black with inhomogeneous structure and plenty fractures partly filled by calcite and quartz. The basalt well develops netty fractures varying in scales while vugs hardly developed according to the imaging logging data (Fig. 3).

Volcanic breccia: the volcanic breccia presents the mixing of irregular high and low resistance blocks in the imaging logging picture. Breccia usually is the bright block with irregular boundary while the cements between the breccia are dull materials, showing alternately dark and bright block in the logging image (Fig. 3).

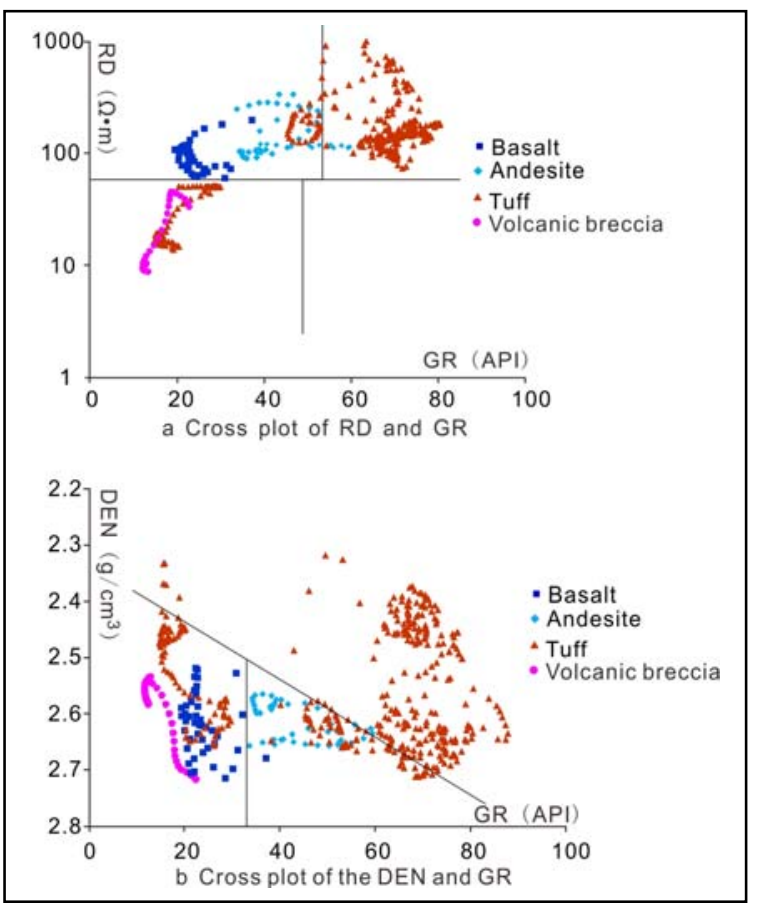

Figure 2. Cross plots of the logging data versus igneous rock lithology, Carboniferous.

\section{Fisher discriminant analysis}

Fisher discriminant is dedicated to finding a proper projection direction that can best reflect the differences of the groups, that is finding one or more linear discriminant functions which make minimum sum of deviation square inside the group and maximum sum of deviation square 
between groups [19]. The Fisher discriminant is a good method of dimension reduction in pattern recognition. With the method, high-dimensional $\mathrm{n}$ parameters were mapped to low-dimensional $m$ parameters which still contain most effective information of the $n$ parameters.

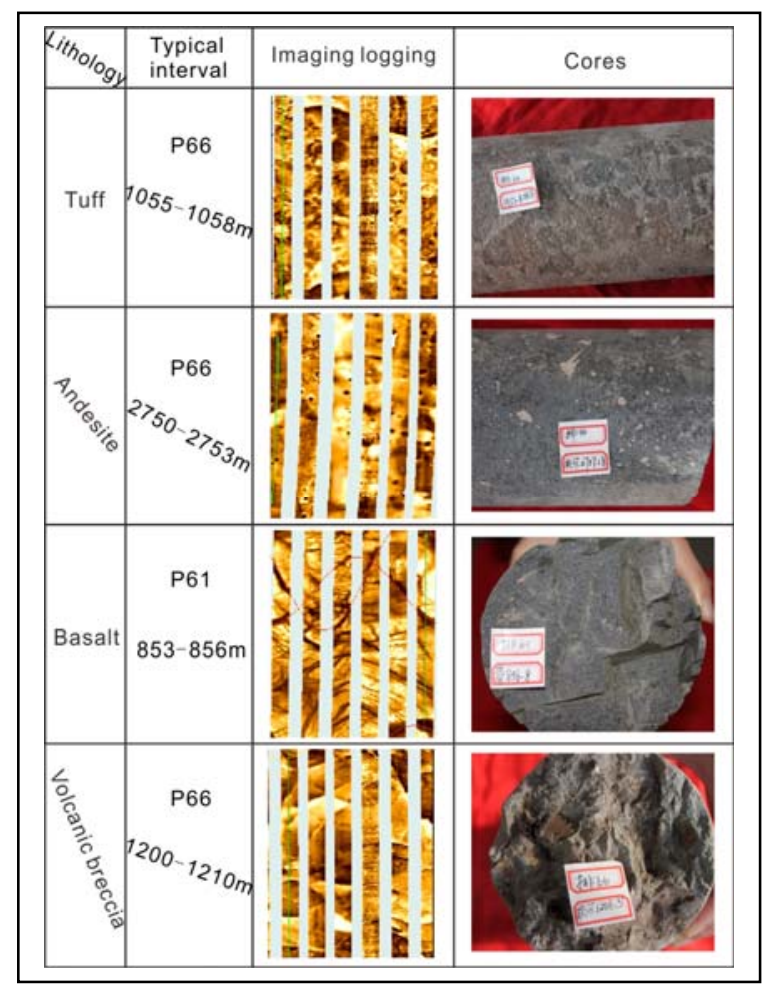

Figure 3. Imaging logging and cores characteristics of the Carboniferous igneous rock.

Take the core's lithology and corresponding logging data as one sample in which lithology is category label $\left(l_{i}\right)$ and logging values compose a vector $\left(\mathrm{X}_{\mathrm{i}}\right)$. The purpose of Fisher discriminant is reasonable reduction of the parameters and greatest distinction of categories [20-23]. Plenty data used in this method can improve the discriminant accuracy, meanwhile, auto interpretation can also been realized when discrimination functions are used by logging software, maximumly eliminating the human factor.

In this paper, category label vector $\left(l_{1}, l_{2}, l_{3}, l_{4}\right)$ representing 4 lithology types (tuff, andesite, basalt and volcanic breccia) coupled with their corresponding logging data values $\left(X_{1}, X_{2}, X_{3}, X_{4}, X_{5}\right)$ representing GR, RT, AC, DEN, and CNL compose training samples $\left(l_{i}, X_{1}, X_{2}, X_{3}, X_{4}\right.$, $X_{5}$ ). According to the Fisher discrimination, two parameters (C1 and C2) (Fig. 4) with cumulative percentage of $91 \%$ and two discriminant functions were obtained.

The discrimination results are shown in Fig. 4. The accuracy is $87.7 \%$, sufficient for lithology detailing. This method can be easily carried out with logging interpretation software, realizing auto identification.

\section{Effect analysis}

Based on the Fisher discriminant of logging data, coupled with cross plot analysis and imaging logging analysis, 5 wells were finally conducted on the distinguishing of the carboniferous igneous rock lithology, obtaining the detailed geological sections. Taking P61 as example (Fig. 5), only two types of lithology were recorded in the geological section. It is very hard to accurately analyse the relationship between pay interval and lithology. After identification, the stacking configuration and the lithology types became more complex which are coincident with the core samples. This task is very useful for the following reservoir research.

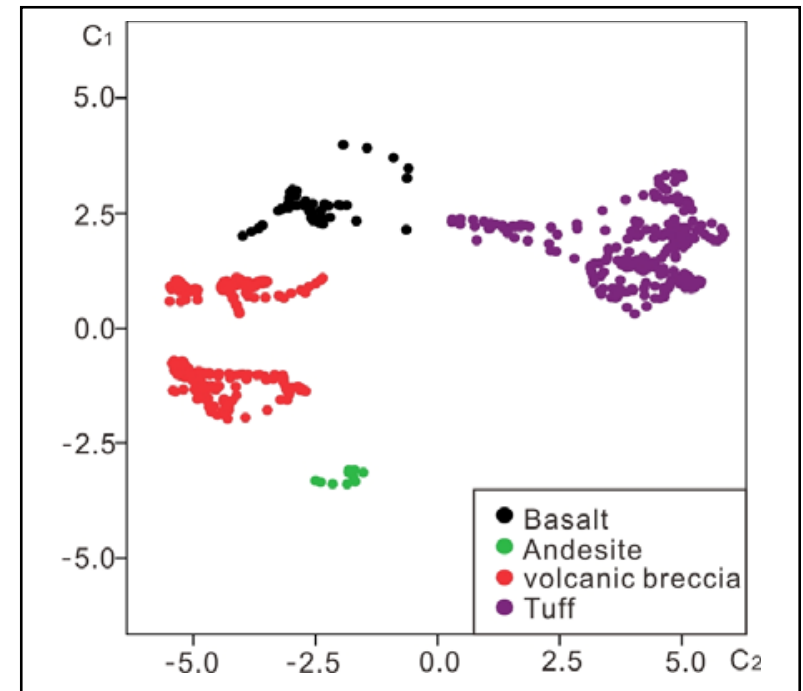

Figure 4. Results of the Fisher discriminant of the cores samples.

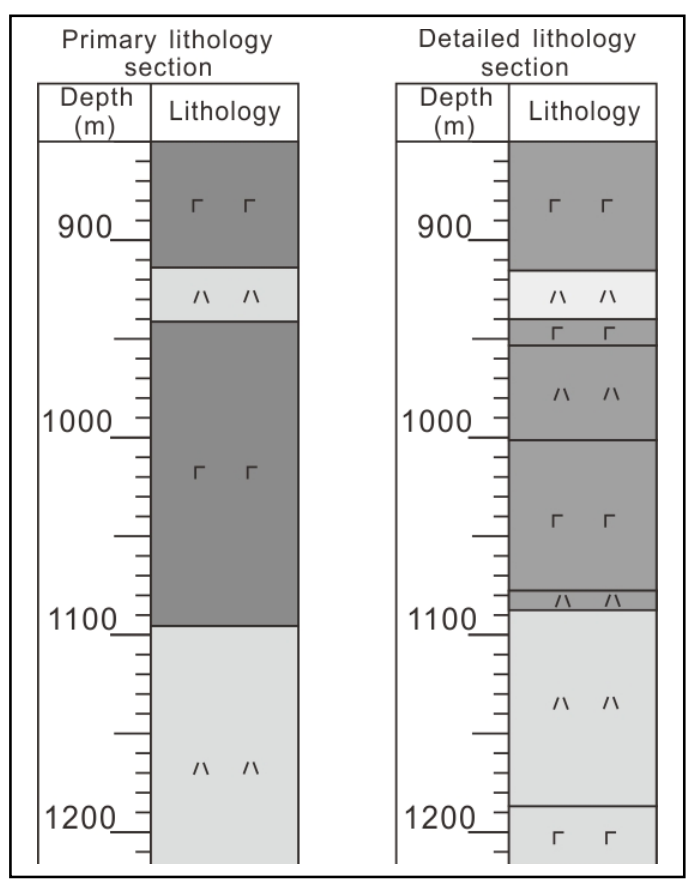

Figure 5. Comparison of the primary lithology section and detailed section, well P61.

\section{CONCLUSIONS}

The Carboniferous igneous rock develops tuff, basalt, andesite and volcanic breccia, which are very difficult to distinguish in geological logging. 
Some lithology can be easily divided from others by logging data cross plot. Some are difficult to distinguish only by cross plot. Imaging logging data visibly reflect the characteristics of the igneous rock, and can be used to distinguish the lithology. The only disadvantage of this method is the big consumption of human resource and time. The Fisher discriminant combining multiple logging data and cores samples is very useful in the detailing of lithology and can be easily conducted by computer.

The modified lithology section is more abundant in lithology and more accurate in lithology, depth and thickness, making it much easier for the following reservoir research.

\section{ACKNOWLEDGMENT}

This work was financially supported by the National Science and Technology Major Project (2011ZX05002). We would like to thank Research Institute of Petroleum Exploration and Development (Beijing, China) for granting permission to publish the results.

\section{REFERENCES}

[1] B. Z. Pan, L. F. Xue, Z. B. Li, and H. B. Wu, "Log evaluation of fractured igneous reservoirs - method and application,” Beijing: Petroleum Industry Press, 2003.

[2] L. J. Huang and Y. R. Fan, "Geological and Geophysical Basis for Studying Igneous Rock Facies by Logging Method,” Well Logging Technology, vol. 21, 1997, pp. 341-344.

[3] D. Z. Wang and X. M. Zhou, "Igneous Petrology,” Beijing: Science Press, 1982.

[4] S. R. Guan, "Simple tutorials igneous and metamorphic," Beijing: Petroleum Industry Press, 1991.

[5] J. Y. Cao, S. A. Liu, and M. Gao, "Methods for seismic data comprehensive interpretation,” Beijing: Petroleum Industry Press, 1991.

[6] Y. Chen, "Reservoir analysis of Carboniferous basalt in region one, Karamay oilfield,” Xinjiang Petroleum Geology, vol. 9, 1988, pp. 17-31.

[7] Y. He, Y. J. Wu, and N. S. Wu, "Volcanic oil and gas reservoirs analysis," Petroleum Geology and Development of Daqing, vol. 18, 1998, pp. 6-14.

[8] C. N. Zou, W. Z. Zhao, C. Z. Jia, R. K. Zhu, G. Y. Zhang, X. Zhao, and $\mathrm{X}$. J. Yuan, "Formation and distribution of volcanic hydrocarbon reservoirs in sedimentary basins of China," Petroleum Exploration and Development, vol. 35, 2008, pp. 257-271.
[9] D. J. Tong, J. Y. Ren, and Y. Z. Li, "Distribution of the Quick subsidence centers and tectonic on the Jurassic Xishanyao formation in Junggar Basin,” Geotectonica Et Metallogenia, vol. 30, 2006, pp. 180-188.

[10] D. F. He, X. F. Chen, J. Kuang, L. Zhou, Y. Tang, and D. G. Liu, "Development and genetic mechanism of Chepaizi - Mosuowan uplift in Junggar basin,” Earth Science Frontiers, vol. 15, 2008, pp. 42-55.

[11] H. P. Liu, "Classification of foreland basins and fold thrust style," Earth Science Frontiers, vol. 2, 1995, pp. 59-68.

[12] X. Jin, Y. C. Lu, and L. Lu, "Analysis of the Mesozoic-Cenozoic subsidence history in Chepaizi Area, Junggar Basin,” Offshore Oil, vol. 27, 2007, pp. 51-56.

[13] Z. Q. Wang, Y. Zheng, D. M. Zhi, Y. F. Dang, and C. Z. Xing, "Hydrocarbon accumulation patterns of Carboniferous formation in Chepaizi area,” Journal of Oil and Gas technology, vol. 32, 2010, pp. 21-25.

[14] C. J. Feng, J. Y. Wang, and Q. F. Feng, "Distinguishing igneous rock lithology by logging data," Journal of Daqing Petroleum Institute, vol. 28, 2004, pp. 9-11.

[15] B. Z. Huang and B. Z. Pan, "The log characteristics of deep igneous rocks and lithology determination in the northern Songliao Basin,” Geophysical Prospecting for Petroleum, vol. 40, 2001, pp. 42-47.

[16] Y. R. Fan, L. J. Huang, and S. H. Dai, "Application of crossplot technique to the determination of lithology composition and fracture identification of igneous rock,” Well Logging Technology, vol. 23, 1999, pp. 53-56.

[17] S. H. Dai, X. P. Luo, J. Wang, and S. Y. Jiang, "Log response and interpretation of volcanic rock reservoir," Xinjiang Petroleum Geology, vol. 19, 1998, pp. 466-467.

[18] Y. Zhang, B. Z. Pan, C. H. Yin, P. Wang, C. P. Liu, and H. J. Li, "Application of imaging logging maps in lithologic identification of volcanics," Geophysical Prospecting for Petroleum, vol. 46, 2007, pp. 288-293.

[19] Z. K. Wang, C. H. Ou, F. X. Li, "Study on the lithology discrimination methods for volcanic reservoir," World Well Logging Technology, vol. 22, 2007, pp. 8-11.

[20] Y. J. Zhao and H. L. Li, “Petroleum mathematics geology,” Beijing: Petroleum Industry Press, 1998.

[21] J. Z. Zhang, Q. S. Guan, J. Q. Tan, Z. D. Yang, Y. Z. Zhang, and M. Geng, "Application of fisher siscrimination to volcanic lithologic identification,” Xin Jiang Petroleum Geology, vol. 29, 2008, pp. 762-764.

[22] Y. Zhang and B. Z. Pan, "Selection and identification of logging data for lithology recognition of volcanic rock in Songliao basin," ACTA Petroleum Sinica, vol. 33, 2012, pp. 831-834.

[23] X. J. Liu, C. Chen, C. Zeng, and L. Lan, "Multivariate statistical method of utilizing logging data to lithologic recognition," Geological Science and Technology Information, vol. 26, 2007, pp. 109-112. 